Article

\title{
Isorhamnetin, Hispidulin, and Cirsimaritin Identified in Tamarix ramosissima Barks from Southern Xinjiang and Their Antioxidant and Antimicrobial Activities
}

\author{
Xiaopu Ren ${ }^{1,2}{ }^{\oplus}$, Yingjie Bao ${ }^{1}$, Yuxia Zhu ${ }^{1}$, Shixin Liu ${ }^{1}$, Zengqi Peng ${ }^{1, *}$, Yawei Zhang ${ }^{1, *}$ \\ and Guanghong Zhou ${ }^{1}$ \\ 1 Key Laboratory of Meat Processing and Quality Control, Ministry of Education China, Jiangsu Collaborative \\ Innovation Center of Meat Production and Processing, Quality and Safety Control, College of Food Science \\ and Technology, Nanjing Agricultural University, Nanjing 210095, China; alarxp@126.com (X.R.); \\ 2015208017@njau.edu.cn (Y.B.); 2016208019@njau.edu.cn (Y.Z.); liushixin_004@163.com (S.L.); \\ ghzhou@njau.edu.cn (G.Z.) \\ 2 Xinjiang Production \& Construction Group Key Laboratory of Agricultural Products Processing in Xinjiang \\ South, College of Life Science, Tarim University, Alar 843300, China \\ * $\quad$ Correspondence: zqpeng@njau.edu.cn (Z.P.); zhangyawei@njau.edu.cn (Y.Z.); Tel.: +86-25-84396558 (Z.P.)
}

Received: 15 December 2018; Accepted: 21 January 2019; Published: 22 January 2019

\begin{abstract}
As a natural potential resource, Tamarix ramosissima has been widely used as barbecue skewers for a good taste and unique flavor. The polyphenolics in the branch bark play a key role in the quality improvement. The purposes of the present work were to explore the polyphenolic composition of $T$. ramosissima bark extract and assess their potential antioxidant and antimicrobial activities. Hispidulin and cirsimaritin from T. ramosissima bark extract were first identified in the Tamarix genus reported with UPLC-MS analysis. Isorhamnetin $(36.91 \mu \mathrm{g} / \mathrm{mg}$ extract), hispidulin $(28.79 \mu \mathrm{g} / \mathrm{mg}$ extract) and cirsimaritin $(13.35 \mu \mathrm{g} / \mathrm{mg}$ extract $)$ are rich in the bark extract. The extract exhibited promising antioxidant activity with $\mathrm{IC}_{50}$ values of $117.05 \mu \mathrm{g} / \mathrm{mL}$ for 1,1-diphenyl-2-picrylhydrazyl (DPPH) and $151.57 \mu \mathrm{g} / \mathrm{mL}$ for hydroxyl radical scavenging activities, as well as excellent reducing power with an $\mathrm{EC}_{50}$ of $93.77 \mu \mathrm{g} / \mathrm{mL}$. The bark extract showed appreciable antibacterial properties against foodborne pathogens. Listeria monocytogenes was the most sensitive microorganism with the lowest minimum inhibitory concentration (MIC) value of $5 \mathrm{mg} / \mathrm{mL}$ and minimum bactericidal concentration (MBC) value of $10 \mathrm{mg} / \mathrm{mL}$ followed by S. castellani and S. aureus among the tested bacteria. The $T$. ramosissima bark extract showed significantly stronger inhibitory activity against Gram-positive than Gram-negative bacteria. Nevertheless, this extract failed to show any activity against tested fungi. Overall, these results suggested that T. ramosissima shows potential in improving food quality due to its highly efficacious antioxidant and antibacterial properties.
\end{abstract}

Keywords: Tamarix ramosissima; polyphenolics; antioxidant activity; antimicrobial activity; isorhamnetin; hispidulin; cirsimaritin

\section{Introduction}

Various species of Tamarix, which are widely distributed throughout Europe, America, Asia, and Africa, have been used as herbal medicines in many civilizations due to the presence of polyphenolic compounds [1]. The methanolic extract of dried aerial components of T. gallica from India was found to prevent thioacetamide-promoted oxidative stress and toxicity and exhibited significant properties to reduce the susceptibility of the hepatic microsomal membrane to iron-ascorbate induced lipid 
peroxidation, $\mathrm{H}_{2} \mathrm{O}_{2}$ content, glutathione $S$-transferase, and xanthine oxidase activities in rats [2]. Yao et al. [3] showed that tamaractam, a new phenolic aromatic ring compound from T. ramosissima tender branches and leaves from the Ningxia province, displayed a strong inhibitory activity on cell proliferation in rheumatoid arthritis fibroblast-like synoviocytes, suggesting that it could remarkably induce cellular apoptosis and increase activated caspase-3/7 levels. Rahman et al [4] indicated that the methanolic extract of $T$. indica roots from Bangladesh exhibited excellent antinociceptive and anti-inflammatory properties. Significant writhing inhibition was produced by the extract in acetic acid-induced writhing in mice when comparable to the standard diclofenac sodium drug at the doses of 500 and $25 \mathrm{mg} / \mathrm{kg}$ body weight, respectively, and showed a significant anti-inflammatory activity against carrageenan-induced paw oedema in rats at oral doses of 200 and $400 \mathrm{mg} / \mathrm{kg}$ body weight compared to the standard drug aspirin. The wide spectrum of these medicinal properties may be mainly attributed to the presence of polyphenolic compounds in Tamarix, such as flavonoids and phenolic acids [1,2].

The leaves and flowers of Tamarix are rich in the polyphenolic compounds [5]. Sultanova et al. [1] identified tamarixetin in the leaves of T. ramosissima from southern Kazakhstan, and showed a high 1,1-diphenyl-2-picrylhydrazyl (DPPH) radical scavenging activity and antimicrobial activity against a number of pathogens, unambiguously specifying that the antioxidant and antibacterial activities of leaves were associated with the presence of polyphenolic compounds. Ksouri et al. [5] showed that syringic acid, isoquercetin and catechin were the major phenolics in the methanolic T. gallica leaf and flower extracts from south Tunis and that the flowers exhibited a higher antioxidant activity than that of the leaves, with $\mathrm{IC}_{50}$ values of the flower extracts being 1.3 ( $\beta$-carotene bleaching) to 19-fold (lipid peroxidation inhibition) lower than those of leaves due to the higher total phenolic content (TPC). Meanwhile, the antibacterial properties of the leaf and flower methanolic extracts against human pathogen strains were also appreciable with a maximum inhibition zone of $15 \mathrm{~mm}$ against Micrococcus luteus. Unfortunately, there were few studies on the identification of polyphenolics, antioxidant and antimicrobial activities of the stem barks of T. ramosissima from southern Xinjiang.

T. ramosissima is one of the main constructive species in the Tarim River basin native to Northwestern China. In southern Xinjiang, for hundreds of years, green branches of Tamarix have been used as barbecue skewers for a good taste and unique flavor. And based on our previous study, the effective substances were largely concentrated in the bark of the green branches. In the present work, we aim to (i) identify and quantify the major polyphenols present in the green branches bark of $T$. ramosissima, and (ii) evaluate their antioxidant and antimicrobial activities against foodborne pathogens. We show that hispidulin and cirsimaritin are first identified in the Tamarix genus reported from $T$. ramosissima bark extract and the extract exhibits satisfying antioxidant and antimicrobial activities, which suggests $T$. ramosissima shows potential in improving food quality to promote health.

\section{Results and Discussion}

\subsection{Content and Variety of Total Polyphenolics from T. ramosissima Barks}

\subsubsection{TPC and Total Flavonoid Content (TFC)}

Many polyphenolic compounds, which are those containing one or more aromatic ring with one or more hydroxyl groups, act as antioxidants in natural plants due to their redox properties [5]. Flavonoids, which are one group of polyphenolics, are secondary metabolites in plants and act as antioxidants [6]. Many types of polyphenols, such as flavonoids and phenolic acids, were reported in Tamarix species [1,2,7-11]. In this work, the TPC of T. ramosissima bark extract was $323.45 \mathrm{mg}$ gallic acid equivalent (GAE)/g, and the TFC was 87.32 quercetin equivalent (QE)/g. When TPC and TFC of the bark extract were compared with the data available for the same genus, it was found that the T. ramosissima bark contained much higher values, as shown in Table 1 . The differences between the Tamarix species were obvious, and the TPC of T. ramosissima was $323.45 \mathrm{mg}$ GAE/g extract, which was 9.39, 2.39 and 1.62 times higher than those of T. gallica leaves, T. gallica flowers, and T. aphylla leaves, 
respectively. The TFC of T. ramosissima in this work was much higher than those of T. gallica leaves and flowers. Additionally, the TPC and TFC varied greatly among different organs, and the bark was a standout organ based on Table 1.

Table 1. Comparison of TPC and TFC with published data of Tamarix family.

\begin{tabular}{cccccc}
\hline $\begin{array}{l}\text { Tamarix } \\
\text { Species }\end{array}$ & Tested Part & Location & TPC (mg GAE/g) & TFC (mg QE/g) & Reference \\
\hline T. ramosissima & barks & South Xinjiang, China & $323.45 \pm 21.41$ & $87.32 \pm 1.65$ & This work \\
T. gallica & leaves & South Tunis & $34.44 \pm 3.40$ & $3.91 \pm 0.45$ & Ksouri et al. [5] \\
T. gallica & flowers & South Tunis & $135.35 \pm 7.70$ & $12.33 \pm 2.10$ & Ksouri et al. [5] \\
T. aphylla & leaves & South Algeria & $199.54 \pm 1.60$ & ND & Mohammedi [9] \\
\hline
\end{tabular}

Note: The TPC and TFC were presented as mean \pm SD. ND means not detected.

\subsubsection{Variety and Content of the Polyphenolics}

UPLC-MS data of the bark extract are shown in Table 2 and Figure 1. A total of 13 polyphenolic compounds were identified and, for the first time, hispidulin and cirsimaritin were isolated from the genus Tamarix: they are active ingredients in a number of traditional Chinese herbs [12,13]. Regarding the other main polyphenolics, isorhamnetin was reported to have been identified from T. hispida, T. elongata and T. laxa which were all collected from southern Kazakhstan [11,14]. Quercetin was a common compound in the Tamarix species and had been identified by several researchers $[5,8,10,11,15]$. Compared to the results of this work, other researchers obtained different polyphenolic compounds from Tamarix. Sultanova et al. identified tamarixetin from T. ramosissima leaves in Kazakhstan [1] and isolated rhamnocitrin, isorhamnetin and a pentacyclic triterpenoid from the aerial components of T. hispida [14]. Ksouri et al. [5] identified polyphenolics from T. gallica leaves and flowers in Tunis, and his results showed that the flower polyphenolics consisted of seven phenolic acids (gallic, sinapic, chlorogenic, syringic, vanillic, $p$-coumaric, and trans-cinnamic acids), six flavonoids $((+)$-catechin, isoquercetin, quercetin, apigenin, amentoflavone, and flavone), 12 phenolic compounds including gallic, sinapic, chlorogenic, syringic, vanillic, rosmarinic, $p$-coumaric, ferulic, and trans-cinnamic acids, as well as two flavonoids (quercetin and amentoflavone) which were identified from the leaves. Yao et al [3] identified only three compounds, tamaractam, cis- $\mathrm{N}$-feruloyl-3-O-methyldopamine and trans-N-feruloyl-3-O-methyl- dopamine from T. ramosissima in Yinchuan, China.

Meanwhile, a further 4 polyphenolic compounds in high amounts, isorhamnetin, hispidulin, cirsimaritin, and quercetin, were quantified in this work (Table 3). However, no literature was found to quantify the concentration of polyphenolics from Tamarix.

Table 2. Peak identification of T. ramosissima bark extract using UPLC-MS.

\begin{tabular}{ccccccc}
\hline Peak No. & Polyphenolic Compounds & $\begin{array}{c}\text { Retention } \\
\text { Time (min) }\end{array}$ & $\begin{array}{c}\text { Empirical } \\
\text { Formula }\end{array}$ & Calcd $m / z$ & $\begin{array}{c}\text { Obsd } m / z \\
{[\mathbf{M}+\mathbf{H}]^{+}}\end{array}$ & $\begin{array}{c}\text { Obsd } m / z \\
{[\mathbf{M}-\mathbf{H}]^{+}}\end{array}$ \\
\hline 1 & Quercetin 3-O-glucuronide & 4.63 & $\mathrm{C}_{21} \mathrm{H}_{18} \mathrm{O}_{13}$ & 478.0747 & 479.0820 & 477.0676 \\
2 & Kaempferol 3-O-glucuronide & 5.19 & $\mathrm{C}_{21} \mathrm{H}_{18} \mathrm{O}_{12}$ & 462.0798 & 463.0882 & 461.0802 \\
3 & Eriodictyol & 6.63 & $\mathrm{C}_{15} \mathrm{H}_{12} \mathrm{O}_{6}$ & 288.0634 & 289.0703 & 287.0581 \\
4 & Quercetin & 6.77 & $\mathrm{C}_{15} \mathrm{H}_{10} \mathrm{O}_{7}$ & 302.0427 & 303.0498 & 301.0404 \\
5 & Naringenin & 7.65 & $\mathrm{C}_{15} \mathrm{H}_{12} \mathrm{O}_{5}$ & 272.0685 & 273.0753 & 271.0583 \\
6 & Tangeretin & 7.72 & $\mathrm{C}_{20} \mathrm{H}_{20} \mathrm{O}_{7}$ & 372.1209 & 373.1274 & 371.1253 \\
7 & Kaempferol & 7.85 & $\mathrm{C}_{15} \mathrm{H}_{10} \mathrm{O}_{6}$ & 286.0477 & 287.0547 & 285.0405 \\
8 & Hesperetin & 8.07 & $\mathrm{C}_{16} \mathrm{H}_{14} \mathrm{O}_{6}$ & 302.0790 & 303.0856 & 301.0718 \\
9 & Isorhamnetin & 9.25 & $\mathrm{C}_{16} \mathrm{H}_{12} \mathrm{O}_{7}$ & 316.0583 & 317.0653 & 315.0510 \\
10 & Hispidulin & 10.41 & $\mathrm{C}_{16} \mathrm{H}_{12} \mathrm{O}_{6}$ & 300.0634 & 301.0705 & 299.0562 \\
11 & Apigenin & 10.42 & $\mathrm{C}_{15} \mathrm{H}_{10} \mathrm{O}_{5}$ & 270.0528 & 271.0597 & 269.0427 \\
12 & Glycitein & 11.90 & $\mathrm{C}_{16} \mathrm{H}_{12} \mathrm{O}_{5}$ & 284.0685 & 285.0754 & 283.0664 \\
13 & Cirsimaritin & 11.91 & $\mathrm{C}_{17} \mathrm{H}_{14} \mathrm{O}_{6}$ & 314.0790 & 315.0863 & 313.0717 \\
\hline
\end{tabular}




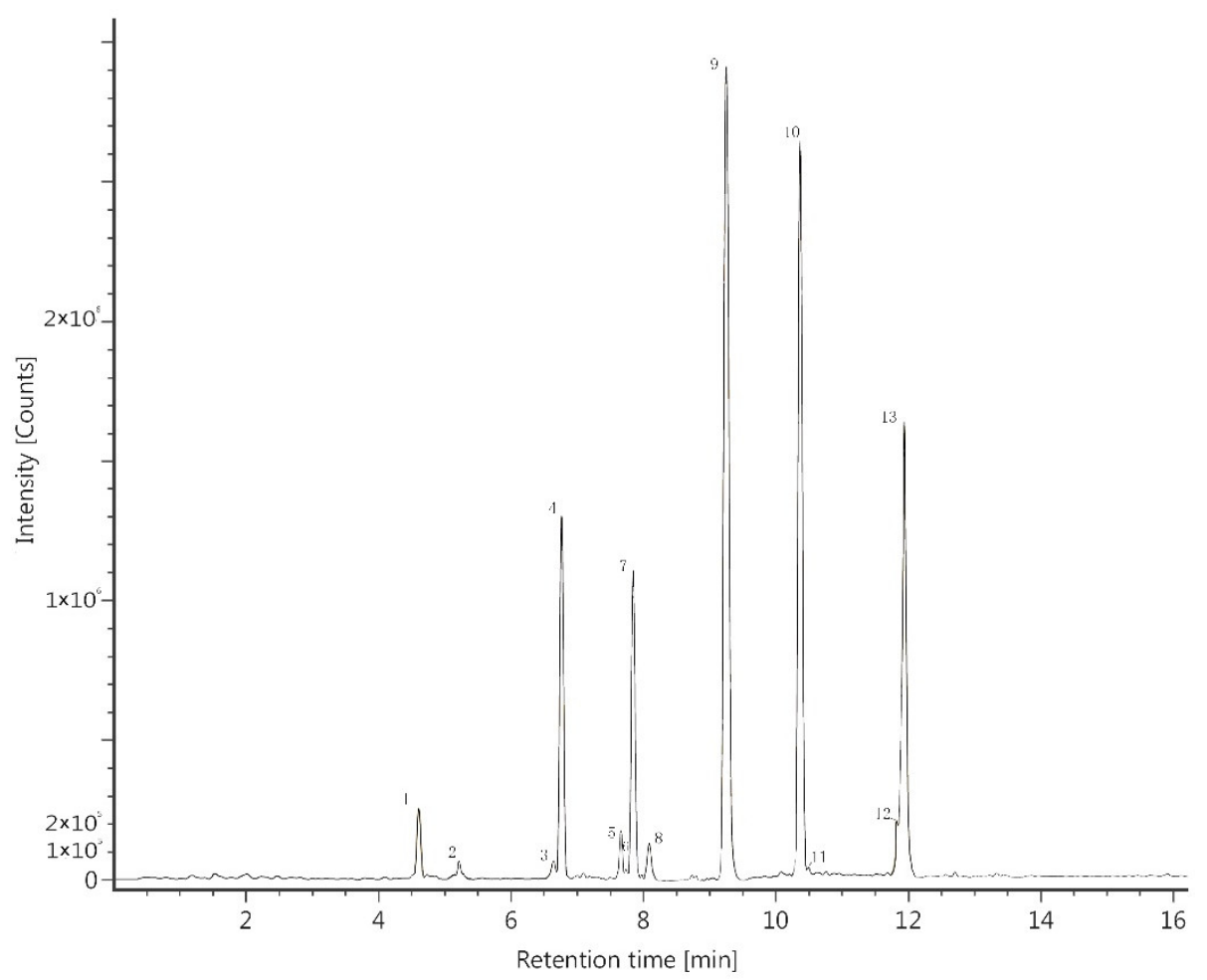

Figure 1. UPLC-MS chromatogram of polyphenolics in T. ramosissima crude extract infusion: quercetin 3-O-glucuronide (1), kaempferol 3-O-glucuronide (2), eriodictyol (3), quercetin (4), naringenin (5), tangeretin (6), kaempferol (7), hesperetin (8), isorhamnetin (9), hispidulin (10), apigenin (11), glycitein (12), cirsimaritin (13).

Table 3. Concentrations of four representative polyphenolic standards.

\begin{tabular}{cc}
\hline Compounds & Concentration $(\mu \mathrm{g} / \mathrm{mg})$ \\
\hline Isorhamnetin & 36.9055 \\
Hispidulin & 28.7915 \\
Cirsimaritin & 13.3513 \\
Quercetin & 4.2065 \\
\hline
\end{tabular}

\subsection{Antioxidant Activity of the Bark Extract}

\subsubsection{DPPH Scavenging Activity}

The DPPH free radicals have been extensively used to investigate the scavenging activity of natural antioxidants. Figure 2A shows the results of the scavenging DPPH radical activity of T. ramosissima bark extracts. The scavenging activity increased sharply when the concentration increased from 25 to $200 \mu \mathrm{g} / \mathrm{mL}$ and trended towards a plateau after $300 \mu \mathrm{g} / \mathrm{mL}(91.70 \% \pm 0.78)$, at which maximal scavenging activity on the DPPH radicals was reached. There was no significant difference of the scavenging activity between the bark extract groups and the control (ascorbic acid) $(p>0.05)$ at concentrations of more than $200 \mu \mathrm{g} / \mathrm{mL}$. There was also no significant difference among the concentrations of 300,400 , and $500 \mu \mathrm{g} / \mathrm{mL}$ of the bark extract groups $(p>0.05)$. The $\mathrm{IC}_{50}$ value $(117.05 \mu \mathrm{g} / \mathrm{mL})$ of T. ramosissima bark extract for scavenging activity against DPPH was much higher than the results of Ksouri et al. [5], who found that the $\mathrm{IC}_{50}$ values on the DPPH radical of the T. gallica flower and leaf extracts were 2 and $9 \mu \mathrm{g} / \mathrm{mL}$, respectively, due to the structural conformation of the antioxidants. In the main polyphenols of the T. gallica flower and leaf extracts, the second hydroxyl group of gallic, chlorogenic, and rosmarinic acid and catechin were in the ortho position, while the compounds of sinapic, syringic, vanillic, and ferulic acid had ortho-methoxy substitutions. These compounds in the flower and leaf extracts included a second hydroxyl group in the ortho or para 
position, and the ortho-methoxy substitution group increased antioxidant efficiencies [16]. However, isorhamnetin and hispidulin in the bark extract had the second hydroxyl group in the meta position. This is potentially the reason for the lower scavenging activity on the DPPH radicals compared to the results of Ksouri et al. [5].
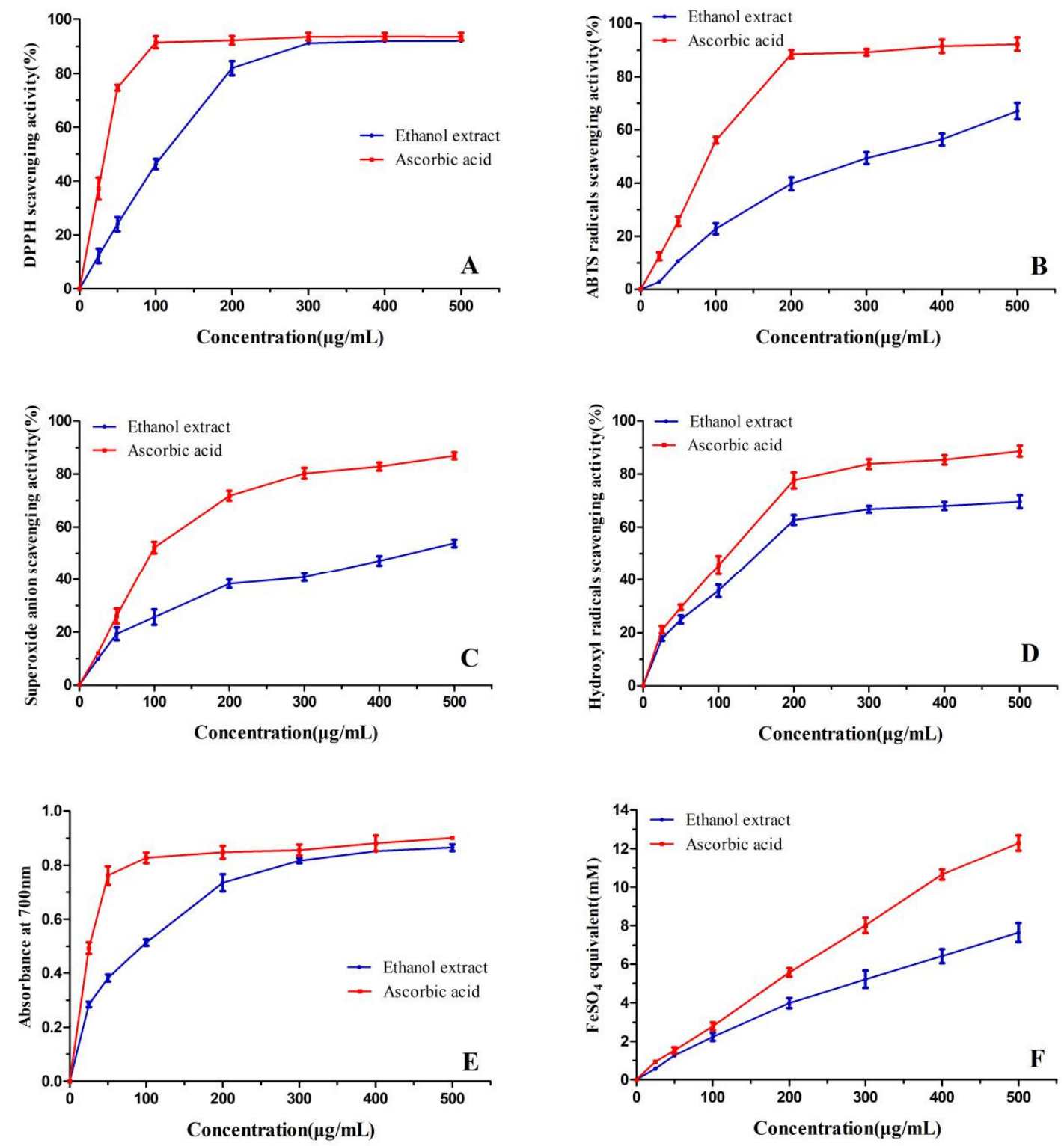

Figure 2. Scavenging activities on 1,1-diphenyl-2-picrylhydrazyl (DPPH) (A), 2,2'-Azinobis(3-ethylbenzthiazoline-6-sulphonate) (ABTS) (B), superoxide radicals (C), hydroxyl radicals (D), reducing power (E) and ferric reducing antioxidant power (FRAP) (F) of the bark extract of T. ramosissima and ascorbic acid. Data are presented as means $\pm \mathrm{SD}$ of triplicates.

\subsubsection{2,2'-Azinobis-(3-ethylbenzthiazoline-6-sulphonate) (ABTS) Scavenging Activity}

The scavenging activity of 2,2'-Azinobis-(3-ethylbenzthiazoline-6-sulphonate) (ABTS) radicals is another widely used method to assess the radical scavenging capacity of natural antioxidants [17]. As shown in Figure 2B, the ABTS radical scavenging activity of the T. ramosissima bark extract increased with the sample concentration. The scavenging activity of the polyphenolics on the ABTS. was correlated with their concentrations [18]. At a concentration of $500 \mu \mathrm{g} / \mathrm{mL}$, the ABTS radical scavenging activity of the bark extract was $67.02 \%$. The scavenging activities of bark extract groups from 25 to $500 \mu \mathrm{g} / \mathrm{mL}$ were significant lower than those of the control $(p<0.05)$. Additionally, there were 
significant differences in the ABTS scavenging activity among the bark extract concentrations $(p<0.05)$. The $\mathrm{IC}_{50}$ value of the bark extract on the ABTS radicals $(314.88 \mu \mathrm{g} / \mathrm{mL})$ was considerably higher than that of ascorbic acid $(82.90 \mu \mathrm{g} / \mathrm{mL})$, similar to the $\mathrm{IC}_{50}$ of the T. gallica flower extract $(316.7 \mu \mathrm{g} / \mathrm{mL})$, and 3.3 times lower than that of the T. gallica leaf extract [5]. The decreased $\mathrm{IC}_{50}$ of the T. ramosissima bark extract and T. gallica flower extract were probably because of the increased level of TPC and TFC (Table 1). Moreover, the difference in polyphenolic components among the extracts may be one of the reasons for the different scavenging activity on the ABTS radicals.

\subsubsection{Superoxide Anion Scavenging Activity}

According to Yagi [19], as opposed to the mechanism of DPPH and ABTS radical reactions, the mechanism of superoxide and hydroxyl radicals was peroxide decomposition. The results of scavenging activity on superoxide radicals of the bark extract are presented in Figure 2C. The scavenging activity on the superoxide radical of the bark extract increased for concentrations ranging from 0 to $500 \mu \mathrm{g} / \mathrm{mL}$. At the concentrations lower than $50 \mu \mathrm{g} / \mathrm{mL}$ of bark extract, there was no significant difference in scavenging activity of superoxide radicals between the bark extract and the control group. The difference in scavenging activity on superoxide radical between the concentrations of 200 and $300 \mu \mathrm{g} / \mathrm{mL}$ of bark extract was not significant. The $\mathrm{IC}_{50}$ value of the bark extract for the superoxide radical was $442.53 \mu \mathrm{g} / \mathrm{mL}$, much higher than that of the results of Ksouri et al. [5], who found that the $\mathrm{IC}_{50}$ on the scavenging activity of the T. gallica flower and leaf extracts were 3 and $22 \mu \mathrm{g} / \mathrm{mL}$, respectively. In the T. gallica flower and leaf extracts, hydroxyl groups were located at the $3^{\prime}$ - and $4^{\prime}$-positions of the B-ring in quercetin, catechin, and isoquercetin that exhibited much higher scavenging activity on superoxide and hydroxyl radicals [19,20]. In the present work, isorhamnetin, hispidulin, and cirsimaritin in the bark extract possessed only one single hydroxyl group at the $4^{\prime}$-position of the B-ring, which exhibited slight scavenging activity.

\subsubsection{Hydroxyl Radicals Scavenging Activity}

As Figure 2D shows, the scavenging activities on hydroxyl radicals increased with the concentrations. The hydroxyl radical scavenging activity increased rapidly in the range of 25 to $200 \mu \mathrm{g} / \mathrm{mL}$, before reaching a plateau from 300 to $500 \mu \mathrm{g} / \mathrm{mL}$. Significant differences in the activity were found among the concentrations of $25,50,100$, and $200 \mu \mathrm{g} / \mathrm{mL}$ of the bark extracts $(p<0.05)$. The scavenging activities of the bark extract in these concentrations were not significantly different from the ascorbic acid $(p>0.05)$. The $\mathrm{IC}_{50}$ of the bark extract on the hydroxyl radical was $151.57 \mu \mathrm{g} / \mathrm{mL}$, which was not significantly higher than that of the ascorbic acid $(114.08 \mu \mathrm{g} / \mathrm{mL})$, suggesting a satisfactory hydroxyl radical scavenging activity. It was evident from Figure $2 \mathrm{C}, \mathrm{D}$ that the scavenging activity of the bark extract on hydroxyl radicals was stronger than on superoxide radicals. At $200 \mu \mathrm{g} / \mathrm{mL}$, the bark extract quenched $62.66 \%$ of hydroxyl radicals while only quenching $38.28 \%$ of superoxide radicals. The stronger scavenging activity on hydroxyl radicals of the bark extract than on superoxide radicals may be associated with the carbonyl function at the C-4 position in the structures of isorhamnetin, hispidulin, and cirsimaritin. The result was in accordance with Husain et al., who found that the presence of a carbonyl functional group at the C-4 position played an important role in the hydroxyl radical quenching ability and that quercetin possessing a carbonyl showed higher quenching ability on the hydroxyl radicals than the carbonyl-devoid catechin [20].

\subsubsection{Reducing Power}

The reducing power of natural antioxidants, which was determined using a modified $\mathrm{Fe}^{3+}$ to $\mathrm{Fe}^{2+}$ reduction assay, has been declared to be associated with their antioxidant activity [21]. As shown in Figure 2E, the reducing power of T. ramosissima bark extract was excellent and increased with the amount of the extract. The reducing power of bark extract at concentrations below $200 \mu \mathrm{g} / \mathrm{mL}$ increased rapidly with concentrations but was significantly lower compared with the control $(p<0.05)$. At the concentration of $300 \mu \mathrm{g} / \mathrm{mL}$, the reducing power of the bark extract was similar to that of ascorbic 
acid $(p>0.05)$. Furthermore, there were also no significant differences among the concentrations of 300,400 , and $500 \mu \mathrm{g} / \mathrm{mL}$ of the bark extract groups $(p>0.05)$. The $\mathrm{EC}_{50}$ of the bark extract was $93.77 \mu \mathrm{g} / \mathrm{mL}$, similar to the $\mathrm{EC}_{50}(76.67 \mu \mathrm{g} / \mathrm{mL})$ of $T$. gallica leaf extract [5]. However, in another report of Ksouri et al. [22] on T. gallica flower and leaf extracts from a different location, the $\mathrm{EC}_{50}$ values of the reducing power were 84.3 and $205 \mu \mathrm{g} / \mathrm{mL}$, respectively.

\subsubsection{Ferric Reducing Antioxidant Power (FRAP)}

The mechanism of the ferric reducing antioxidant power (FRAP) assay was similar to the reducing power, both of which relied on the ability of antioxidants to reduce iron (III) to iron (II). More specifically, in the FRAP assay, a ferric tripyridyltriazine (FeIII-TPTZ) complex was reduced to the ferrous form (FeII-TPTZ) at low $\mathrm{pH}$ value, and several researchers considered the assay as the total antioxidant power $[23,24]$. In the present work, the trends for ferric ion reducing activities of T. ramosissima bark extract and ascorbic acid are shown in Figure 2F. For both of them, the $\mathrm{FeSO}_{4}$ equivalent $(\mathrm{mM} / \mathrm{g})$ clearly increased due to the formation of the $\mathrm{Fe}^{2+}$-TPTZ complex with increasing concentration. The $\mathrm{FeSO}_{4}$ equivalent increased linearly with the concentrations $\left(\mathrm{R}^{2}=0.9879\right.$ for the bark extract, 0.9961 for ascorbic acid). There was no significant difference between the bark extract group and the control at concentrations ranging from 0 to $100 \mu \mathrm{g} / \mathrm{mL}(p>0.05)$. However, the differences became larger with increasing concentrations. At the concentration of $500 \mu \mathrm{g} / \mathrm{mL}$, the $\mathrm{FeSO}_{4}$ equivalent was $7.64 \mathrm{mM} / \mathrm{g}$ for the bark extract and $12.28 \mathrm{mM} / \mathrm{g}$ for the positive control, both of which were higher than those of Barringtonia racemosa and kudingcha crude extracts determined by the same methods [25,26]. Hidalgo et al. [27] found that in the FRAP assay, the polyphenols with 3-hydroxyl group in the C-ring (such as isorhamnetin and quercetin in the bark extract of the present work) showed high antioxidant power and that the antioxidant activity did not decrease when the 3-hydroxyl group in the C-ring was blocked if the $3^{\prime}, 4^{\prime}$-dihydroxy structure in the B-ring was retained (as in the case of quercetin 3-O-glucuronide in the bark extract of the present work).

As previously mentioned, the antioxidant activity of the bark extract of $T$. ramosissima was satisfactory and the presence of polyphenolics, especially flavonoids, probably played a significant role. The findings of Ksouri et al. [5] largely supported the claims of the present work, which suggests that the extracts of $T$. gallica showed very high antioxidant activity due to the presence of polyphenolics and that the antioxidant properties exhibit a high positive correlation with polyphenolic content. Sultanova et al. [1] also specifically stated that the antioxidant activity was associated with the presence of polyphenolic substances. In the bark extract of T. ramosissima, different polyphenols exhibited various antioxidant activities. Isorhamnetin, a 3'-O-methylated metabolite of quercetin, exerts excellent antioxidant effects, which reduces oxidative stress due to free radicals by induction of NF-E2-related factor 2 (Nrf2)-dependent antioxidant genes [28]. Cirsimaritin is a small molecular natural flavonoid, mainly derived from the medicinal plant Herba Artemisiae Scopariae, which exhibits a variety of beneficial activities including antioxidant activity [29]. Quercetin is the typical flavonoid structure and is widely used as a nutritional supplement due to its antioxidant and anti-inflammatory properties [30]. Hispidulin, also named 6-methoxy-5,7,4'-trihydroxyflavone, has been shown to possess anti-inflammatory and antioxidative activities [31], although the antioxidant activity of hispidulin is very weak compared with quercetin [32]. All of these polyphenolic compounds contributed to the antioxidant activity of the T. ramosissima bark extract. In general, the antioxidant property of a given compound is thought to be closely linked to its structural features, including the ortho-dihydroxy structure in the B-ring, the 2,3 double bond in conjugation with a 4-oxo function, the presence of the 3and 5-OH functions and glycosidic moieties and the number and position of hydroxyl and methoxy groups [27]. Moreover, the nature of the radical and its specific reaction mechanism also exert great influence on the antioxidant activity of the tested polyphenolics. All of these elements determine the final effects of the polyphenolics. 


\subsection{Antimicrobial Activity}

The antimicrobial activities of T. ramosissima bark extract at different concentrations are shown in Table 4. For the Gram-positive bacteria, the inhibition zone against Listeria monocytogenes at the concentration of $10 \mathrm{mg} / \mathrm{mL}$ of the bark extract was the largest $(p<0.05)$. The inhibition zones against L. monocytogenes and Staphylococcus aureus were larger than that of Bacillus cereus at the concentration of $5 \mathrm{mg} / \mathrm{mL}$, and significantly increased with the concentrations $(p<0.05)$. However, the inhibition zone against $S$. aureus was not influenced by the concentration of the bark extract. Among these Gram-positive strains, L. monocytogenes was the most sensitive microorganism with the lowest minimum bactericidal concentration (MBC) values of $10 \mathrm{mg} / \mathrm{mL}$. Excellent antibacterial activity against Gram-positive bacteria was also supported by Ksouri et al. [5], who found that the inhibition zone ranged from 7.00 to $15.00 \mathrm{~mm}$ at the concentrations of 2,4 and $100 \mathrm{mg} / \mathrm{mL}$ of the T. gallica leaf and flower extracts. For $S$. aureus, the bark extract in this work showed much larger inhibition zones compared with the T. gallica leaf and flower extracts. The methanol extract of T. indica from Bangladesh also exhibited similar antibacterial activity against $S$. aureus with an inhibition zone of $10.80 \mathrm{~mm}$ [4]. Nevertheless, the T. ramosissima leaf extract from southern Kazakhstan showed no antibacterial activity against $S$. aureus and B. cereus [1]. The inhibitory effects of the bark extract on bacterial pathogens could be attributed to the isorhamnetin, hispidulin, or cirsimaritin in the T. ramosissima bark extract, of which the purified hispidulin showed antibacterial activity against $B$. subtilis with minimum inhibitory concentration (MIC) values of $50 \mu \mathrm{g} / \mathrm{mL}$ and S. aureus with MIC values of $100 \mu \mathrm{g} / \mathrm{mL}$ [33].

Table 4. Antibacterial activity of T. ramosissima bark extracts at different concentrations. Minimum bactericidal concentration (MBC), minimum inhibitory concentration (MIC).

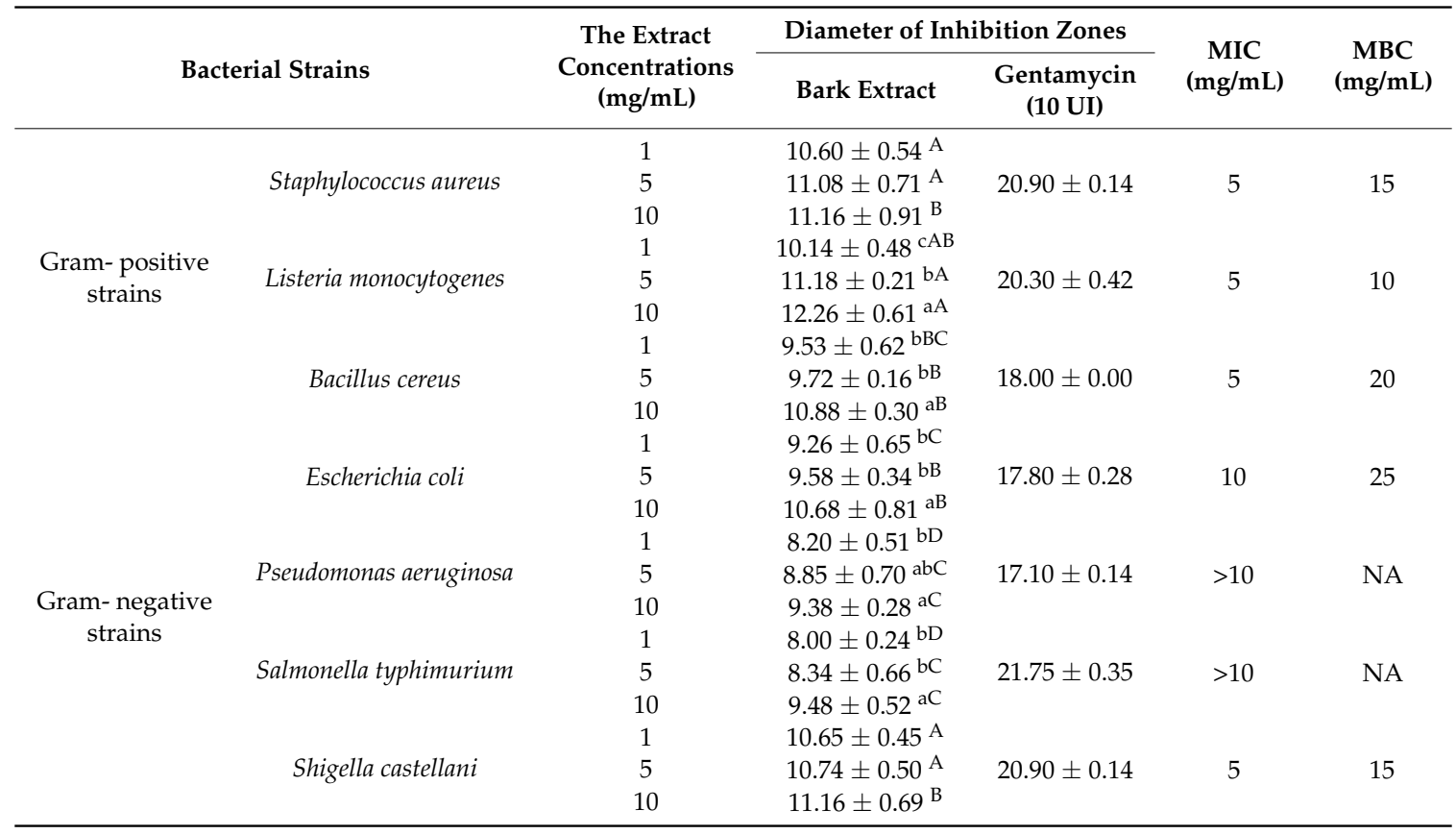

Note: Inhibition zone calculated in diameter around the disc (mean \pm SD). Different lowercase letters (a c) within the same bacteria mean significant differences between different concentrations $(p<0.05)$; Different capital letters (A-D) within the same concentration mean significant differences between different bacteria $(p<0.05)$ and no letters indicates no significant difference $(p>0.05)$. NA represented not active. The diameter of disc was $6 \mathrm{~mm}$. Each experiment was done in triplicate.

The inhibition zones against Gram-negative bacteria were increased with the concentrations $(p<0.05)$, except in the case of Shigella castellani. In the Gram-negative bacteria, the inhibition zones against $S$. castellani were the largest $(p<0.05)$ at the concentrations of $1 \mathrm{or} 5 \mathrm{mg} / \mathrm{mL}$ of the bark extract. The inhibition zones against Escherichia coli and S. castellani were larger than those of Pseudomonas aeruginosa and Salmonella typhimurium at the concentration of $10 \mathrm{mg} / \mathrm{mL}(p<0.05)$. S. castellani was the 
most sensitive to the bark extract, with the lowest MIC of $5 \mathrm{mg} / \mathrm{mL}$ and MBC values of $15 \mathrm{mg} / \mathrm{mL}$. These results were consistent with those of Rahman et al., who found that the T. indica extract exhibited the largest inhibition zones against S. sonnie [4]. In the present work, E. coli was the second most sensitive to the bark extract with a MIC of $10 \mathrm{mg} / \mathrm{mL}$ and MBC values of $25 \mathrm{mg} / \mathrm{mL}$. The T. gallica leaf and flower extracts from Tunis also had inhibitory effects on E. coli [5].

Compared to Gram-negative bacteria, Gram-positive bacteria were sensitive to the bark extract, with the mean of inhibition zones significantly larger at the concentrations of 1,5 and $10 \mathrm{mg} / \mathrm{mL}$ $(p<0.05)$. Similar results can also be observed from the MIC values of these bacteria. These differences in inhibitory effects of the bark extract between Gram-negative bacteria and Gram-positive bacteria may be associated with the different cell wall components of the bacteria [34]. The antibacterial activity of the T. ramosissima bark extract was lower than that of gentamycin $(p<0.05)$. The T. ramosissima bark extract failed to show any activity against four tested fungi. The results of this work suggested that there may be a huge potential application of T. ramosissima to prevent the growth of foodborne pathogens.

\section{Materials and Methods}

\subsection{Plant Materials and Extraction Procedure}

Fresh twigs of $T$. ramosissima were collected from the Tarim River basin on the edge of the Taklamakan desert in Xinjiang ( $40^{\circ} 25^{\prime} 28.81^{\prime \prime} \mathrm{N}, 81^{\circ} 14^{\prime} 18.14^{\prime \prime}$ E, Southwest of Alar city) in June 2017. The plant was identified by an expert taxonomist, Mr. Pang, who had been engaged on taxonomic research of Tamarix in South Xinjiang for a significant length of time at Tarim University. The peeled bark off green branches were air-dried and milled to a fine powder (mesh size: $1 \mathrm{~mm}$ ). Approximately $500 \mathrm{~g}$ of powdered barks were soaked in $2500 \mathrm{~mL}$ of $60 \%$ ethanol for $40 \mathrm{~min}$. Ultrasonic-assisted extraction was used, and the power was $600 \mathrm{~W}$ (VCX 750, Sonics, USA). The extracts were filtered through a Whatman no. 4 filter paper and evaporated under vacuum. Then, the vacuum freeze dryer (LGJ-10C, Four-ring, China) was employed to obtain the ethanol extracts and they were stored at $-20{ }^{\circ} \mathrm{C}$ until analysis. All solvents and reagents were of analytical grade.

\subsection{Determination of Total Polyphenolic Content}

The TPC in the T. ramosissima bark extract was determined according to the Folin-Ciocalteu procedure as described by Jayasinghe et al [35] with some modifications, using gallic acid as a standard. $0.05 \mathrm{~g}$ of the bark extract was dissolved in $2 \mathrm{~mL}$ of ethanol-water solution and mixed with $2 \mathrm{~mL}$ of Folin-Ciocalteu's phenol reagent. The mixture was kept for $3 \mathrm{~min}$ at room temperature, and then $2 \mathrm{~mL}$ of $\mathrm{Na}_{2} \mathrm{CO}_{3}$ solution $(10 \%, w / v)$ was added to the mixture. The reaction mixture was allowed $1 \mathrm{~h}$ to incubate at ambient temperature in the dark, and the absorbance was then read at $530 \mathrm{~nm}$. Deionized water was used as a blank sample. A standard calibration curve of gallic acid $(0-0.4 \mathrm{mg} / \mathrm{mL}) \mathrm{was}$ plotted $\left(R^{2}=0.9995\right)$. The results were expressed as milligrams of gallic acid equivalent per gram of the bark extract (mg GAE/g). All analyses were performed in triplicate.

\subsection{Determination of Total Flavonoid Content}

The TFC in the T. ramosissima bark extract was determined using the aluminum chloride colorimetric method as described by Chang et al [36] with some modifications using quercetin as a standard. In this experiment, $0.05 \mathrm{~g}$ of the bark extract was dissolved in $2 \mathrm{~mL}$ of $80 \%$ ethanol and then separately mixed with $0.1 \mathrm{~mL}$ of $10 \%$ aluminum chloride, $0.1 \mathrm{~mL}$ of $1 \mathrm{M}$ potassium acetate and $2.8 \mathrm{~mL}$ deionized water. The reaction mixture was incubated at room temperature for $30 \mathrm{~min}$, and the absorbance was then measured at $415 \mathrm{~nm}$. Deionized water was used as a blank sample. A standard calibration curve of quercetin $(0-0.1 \mathrm{mg} / \mathrm{mL})$ was plotted $\left(\mathrm{R}^{2}=0.9991\right)$. The concentration of flavonoid was expressed as milligrams of quercetin equivalent per gram of extract (mg QE/g). All analyses were performed in triplicate. 


\subsection{Analysis of Bark Extract by UPLC-MS}

The samples were analyzed using a UPLC-MS following a method previously published, with some modifications [37]. The samples were analyzed by an LC-MS system (G2-XS QTof, Waters). First, $2 \mu \mathrm{L}$ solutions were injected into the UPLC column $(2.1 \mathrm{~mm} \times 100 \mathrm{~mm}$ ACQUITY UPLC BEH C18 column containing $1.7 \mu \mathrm{m}$ particles) with a flow rate of $0.4 \mathrm{~mL} / \mathrm{min}$. Buffer A consisted of $0.1 \%$ formic acid in water, and buffer B consisted of $0.1 \%$ formic acid in acetonitrile. The gradient was $5 \%$ Buffer B for $0.5 \mathrm{~min}, 5-95 \%$ Buffer B for $11 \mathrm{~min}$, and 95\% Buffer B for $2 \mathrm{~min}$. Mass spectrometry was performed using an electrospray source in negative ion mode with the MSe acquisition mode and a selected mass range of 50-1200 $\mathrm{m} / z$. The lock mass option was enabled using leucine-enkephalin $(\mathrm{m} / z$ 554.2615) for recalibration. The ionization parameters were the following: capillary voltage was $2.5 \mathrm{kV}$, collision energy was $40 \mathrm{eV}$, source temperature was $120^{\circ} \mathrm{C}$, and desolvation gas temperature was $400{ }^{\circ} \mathrm{C}$. For quantification purposes, the four major compounds, isorhamnetin, hispidulin, cirsimaritin, and quercetin (Sigma, USA) were quantified using the calibration curves of their corresponding standards. Data acquisition and processing were performed using Masslynx 4.1 and results were presented as $\mu \mathrm{g} / \mathrm{mg}$ extract.

\subsection{Determination of Antioxidant Assays}

\subsubsection{DPPH Radical Scavenging Activity}

The DPPH free radical scavenging activity of the T. ramosissima bark extract was conducted according to the method of Yang et al [38], with some modifications. $0.5 \mathrm{~mL}$ of the bark extract solution at various concentrations $(25,50,100,200,300,400$, and $500 \mu \mathrm{g} / \mathrm{mL})$ was mixed with $3.5 \mathrm{~mL}$ of freshly prepared DPPH-ethanol solution $\left(1 \times 10^{-4} \mathrm{~mol} / \mathrm{L}\right)$. The reaction mixture was mixed vigorously for $15 \mathrm{~s}$ and then kept in the dark for $30 \mathrm{~min}$ at room temperature. The absorbance was then measured at $517 \mathrm{~nm}$, and the DPPH free radical scavenging percentage was calculated based on the following equation:

$$
\text { DPPH radical scavenging activity }(\%)=\left[1-\left(\mathrm{A}_{1}-\mathrm{A}_{2}\right) / \mathrm{A}_{0}\right] \times 100
$$

where $A_{1}$ was the Abs of the sample, $A_{2}$ was the Abs of the sample only (ethanol instead of DPPH), and $A_{0}$ was the Abs of the control (deionized water instead of sample solution). The bark extract concentration that inhibited $50 \%$ of the DPPH radicals $\left(\mathrm{IC}_{50}\right)$ was calculated and expressed as $\mu \mathrm{g} / \mathrm{mL}$. The ascorbic acid was used as a positive control and conducted in parallel. The experiment was carried out in triplicate.

\subsubsection{ABTS Radical Scavenging Activity}

The ABTS free radical-scavenging activity of the T. ramosissima bark extract was determined according to Liu et al. [26]. A mixture $(1: 1, v / v)$ of ABTS $(7.0 \mathrm{mM})$ and potassium persulfate $(4.95 \mathrm{mM})$ was incubated at $25^{\circ} \mathrm{C}$ overnight in the dark to prepare the fresh stock solution. A working solution was prepared by diluting the stock solution with phosphate buffer solution ( $\mathrm{pH} 7.4,0.2 \mathrm{M}$ ) to obtain an absorbance of $0.70 \pm 0.02$ at $734 \mathrm{~nm}$. Then, $20 \mu \mathrm{L}$ of the bark extract solutions at various concentrations $(25,50,100,200,300,400$, and $500 \mu \mathrm{g} / \mathrm{mL})$ were mixed with $200 \mu \mathrm{L}$ working solution and kept in the dark for $30 \mathrm{~min}$. The absorbance was then measured at $734 \mathrm{~nm}$. The ascorbic acid was used as a positive control, and the ABTS radical scavenging activity was calculated according to the following equation:

$$
\text { ABTS radical scavenging activity }(\%)=\left[1-\left(\mathrm{A}_{1}-\mathrm{A}_{2}\right) / \mathrm{A}_{0}\right] \times 100
$$

where $A_{0}, A_{1}$ and $A_{2}$ have the same meaning as in Equation (1). The $\mathrm{IC}_{50}$ value was also calculated and expressed as $\mu \mathrm{g} / \mathrm{mL}$. All the analyses were performed in triplicate. 


\subsubsection{Superoxide Anion Radical Scavenging Activity}

The superoxide anion radical scavenging of the T. ramosissima bark extract was evaluated based on the method of Liu et al. [39], with slight modifications. The reaction mixture contained $1 \mathrm{~mL}$ of $50 \mu \mathrm{M}$ nitro-blue tetrazolium (NBT), $1 \mathrm{~mL}$ of $78 \mu \mathrm{M}$ nicotinamide adenine dinucleotide (NADH), $1 \mathrm{~mL}$ of $10 \mu \mathrm{M}$ phenazine methosulfate (PMS), and $1 \mathrm{~mL}$ of the bark extract at different concentrations $(25,50,100,200,300,400$ and $500 \mu \mathrm{g} / \mathrm{mL})$. After incubation in the dark for $10 \mathrm{~min}$ at $37^{\circ} \mathrm{C}$, the absorbance was measured at $560 \mathrm{~nm}$. The ascorbic acid was used as a positive control and triplicate tests were conducted for each sample. The superoxide anion radical scavenging activity was calculated according to Equation (3):

$$
\text { Superoxide anion radical scavenging activity }(\%)=\left[1-\left(\mathrm{A}_{1}-\mathrm{A}_{2}\right) / \mathrm{A}_{0}\right] \times 100
$$

where $A_{0}, A_{1}$ and $A_{2}$ have the same meaning as in Equation (1). The $\mathrm{IC}_{50}$ value was calculated and expressed as $\mu \mathrm{g} / \mathrm{mL}$.

\subsubsection{Hydroxyl Radical Scavenging Activity}

The hydroxyl radical scavenging activity of the T. ramosissima bark extract was assayed according to $\mathrm{Li}$ [40], with some modifications. The hydroxyl radicals were generated in a Fenton reaction by incubating for $60 \mathrm{~min}$ at $37{ }^{\circ} \mathrm{C}$ in the presence of $1.0 \mathrm{mM} \mathrm{FeSO}_{4}, 2.0 \mathrm{mM} \mathrm{H}_{2} \mathrm{O}_{2}, 1.0 \mathrm{mM}$ Ethylene diamine tetraacetic acid (EDTA), $1.0 \mathrm{mM}$ sodium salicylate, $20 \mathrm{mM} \mathrm{NaH} \mathrm{PO}_{4}-\mathrm{Na}_{2} \mathrm{HPO}_{4}$ buffer (pH 7.4), and sample solutions of various concentrations $(25,50,100,200,300,400$, and $500 \mu \mathrm{g} / \mathrm{mL})$ in a final volume of $5 \mathrm{~mL}$. The solutions of $\mathrm{FeSO}_{4}$ and $\mathrm{H}_{2} \mathrm{O}_{2}$ were freshly produced in distilled water just before use. After incubation, the absorbance was measured at $532 \mathrm{~nm}$ and all samples were determined in three replicates. The results were calculated according to Equation (4):

$$
\text { Hydroxyl radical scavenging activity }(\%)=\left[1-\left(\mathrm{A}_{1}-\mathrm{A}_{2}\right) / \mathrm{A}_{0}\right] \times 100
$$

where $A_{0}, A_{1}$ and $A_{2}$ have the same meaning as in Equation (1). The $\mathrm{IC}_{50}$ value was calculated and expressed as $\mu \mathrm{g} / \mathrm{mL}$.

\subsubsection{Reducing Power}

The reducing power of T. ramosissima bark extract was determined according to the method of Ye et al [41] with several modifications. The sample was dissolved in phosphate buffer saline (PBS) (pH 6.6, $0.2 \mathrm{M}$ ) to afford various concentrations $(25,50,100,200,300,400$, and $500 \mu \mathrm{g} / \mathrm{mL}$ ). $2.5 \mathrm{~mL}$ sample solutions and $2.5 \mathrm{~mL}$ of $1 \%$ potassium ferricyanide were mixed and incubated at $50{ }^{\circ} \mathrm{C}$ for $20 \mathrm{~min}$. Then, the mixture was cooled to $25{ }^{\circ} \mathrm{C}$ and $2.5 \mathrm{~mL}$ of $10 \%$ trichloroacetic acid was added. The mixture was centrifuged at $650 \times g$ for $10 \mathrm{~min}$. The supernatant $(2.5 \mathrm{~mL})$ was mixed with $2.5 \mathrm{~mL}$ of distilled water and $0.5 \mathrm{~mL}$ of $0.1 \%$ ferric chloride. After thoroughly mixing, the absorbance was measured at $700 \mathrm{~nm}$ by a microplate reader, and the ascorbic acid was used as a positive control. Triplicate tests were conducted for each sample, and a higher absorbance indicated a higher reducing power. The reducing power was calculated according to the formula below:

$$
\text { Reducing power }=\mathrm{A}_{1}-\mathrm{A}_{2}
$$

where $A_{1}$ is the absorbance of the sample and $A_{2}$ is the absorbance of the sample only (distilled water instead of ferric chloride). The $\mathrm{EC}_{50}$ value is the effective dose of the bark extract yielding an absorbance of 0.5 for reducing power and expressed as $\mu \mathrm{g} / \mathrm{mL}$. 


\subsubsection{Ferric Reducing Antioxidant Power (FRAP) Assay}

The FRAP assay was performed according to Liu et al. [26], with some modifications. Briefly, $0.2 \mathrm{~mL}$ T. ramosissima bark extract solution at different concentrations $(25,50,100,200,300,400$, and $500 \mu \mathrm{g} / \mathrm{mL}$ ) was added to $3.8 \mathrm{~mL}$ of FRAP reagent (10 volumes of $300 \mathrm{mM}$ sodium acetate buffer at $\mathrm{pH} 3.6,1$ volumes of $10.0 \mathrm{mM} \mathrm{2,4,6-tripyridyl-s-triazine} \mathrm{(TPTZ)} \mathrm{solution,} \mathrm{and} 1$ volume of $20.0 \mathrm{mM} \mathrm{FeCl} \cdot 6 \mathrm{H}_{2} \mathrm{O}$ solution), and then the mixture was warmed to $37^{\circ} \mathrm{C}$ for $30 \mathrm{~min}$ in the dark. The absorbance was then measured at $593 \mathrm{~nm}$. The antioxidant activity was calculated from the calibration curve $(y=0.1446 x+0.0478)$ in the range from 0.15 to $1.50 \mathrm{mM} \mathrm{FeSO}_{4}$ with good linearity $\left(\mathrm{R}^{2}=0.9943\right)$. The results were expressed as $\mathrm{mM} \mathrm{FeSO}_{4}$ equivalent/g extract. The ascorbic acid was used as a positive control, and all analyses were performed in triplicate.

\subsection{Determination of Antimicrobial Activity}

\subsubsection{Microorganisms}

The target bacterial strains used in the study were seven American Type of Culture Collection (ATCC) strains: Gram-positive bacteria including S. aureus (ATCC 25923), L. monocytogenes (ATCC 13932), B. cereus (ATCC 11778), and Gram-negative bacteria including E. coli (ATCC 35218), P. aeruginosa (ATCC 27853), S. typhimurium (ATCC 14028), and S. castellani (ATCC 12022). The strains were first grown in Mueller Hinton (MH, Hopebio, Qingdao, China) broth at $37^{\circ} \mathrm{C}$ for $24 \mathrm{~h}$ prior to seeding onto the $\mathrm{MH}$ agar.

For the antifungal activity, four clinical isolates of Penicillium expansum, Aspergillus niger, Acremonium strictum, and Penicillium citrinum were first grown on Sabouraud dextrose agar (SDA, HANGWEI, China) plates at $28^{\circ} \mathrm{C}$ for $48 \mathrm{~h}$.

\subsubsection{Agar Disc Diffusion Method}

The Kirby-Bauer agar disc diffusion method was performed to determine the antibacterial and antifungal activity of the $T$. ramosissima bark extract following procedures previously described by Ebani et al [42]. Briefly, isolated colonies were selected to prepare the bacterial inocula in sterile saline solutions to obtain a turbidity equivalent to a 0.5 McFarland standard, approximately 1 to $2 \times 10^{7} \mathrm{CFU} / \mathrm{mL}$. Meanwhile, the fungal spores were picked into the sterile saline solution and adjusted to $10^{4}$ to $10^{5} \mathrm{CFU} / \mathrm{mL}$. An aliquot of $0.1 \mathrm{~mL}$ of bacterial (or spore) suspension was spread onto an $\mathrm{MH}$ agar plate (SDA for fungi) and then a sterile filter disc with $6 \mathrm{~mm}$ diameter (Whatman paper no. 3), which was impregnated with the bark extract of different concentrations $(1,5,10 \mathrm{mg} / \mathrm{mL})$ in dimethyl sulfoxide (DMSO, Oxoid), was placed on the surface of the media. The plates were incubated at $37^{\circ} \mathrm{C}$ for $24 \mathrm{~h}$, and $28^{\circ} \mathrm{C}$ for $48 \mathrm{~h}$ for fungi, followed by the measurement of the diameter of the growth inhibition zone expressed in millimeters $(\mathrm{mm})$. DMSO was used as negative control, with gentamycin and ketoconazole (Amresco, USA) as positive controls for bacteria and fungi, respectively. All tests were performed in triplicate.

\subsubsection{Determination of Minimum Inhibitory Concentration (MIC)}

The MIC of the T. ramosissima bark extract was determined for each bacterial strain, which was sensitive to the bark extract of the Kirby-Bauer assay, using the microdilution broth method in 96-well microplates. The tests were carried out in $\mathrm{MH}$ broth, and a stock solution $(20 \mathrm{mg} / \mathrm{mL})$ of the bark extract was prepared in 10\% DMSO. An aliquot of this solution was serially diluted (two-fold) with $\mathrm{MH}$ broth to obtain a concentration ranging from 20 to $0.15625 \mathrm{mg} / \mathrm{mL}$. After careful mixing, the microplates were incubated at $37^{\circ} \mathrm{C}$ for $24 \mathrm{~h}$. The absorbances of the plates at $620 \mathrm{~nm}$ were measured with a multiplate reader (SpectraMax M3, Molecular Devices, USA). The MIC value was defined as the lowest concentration of the bark extract at which there was no visible growth of the microorganisms [43]. The results were expressed as $\mathrm{mg} / \mathrm{mL}$, and all tests were performed in triplicate. 


\subsubsection{Determination of Minimum Bactericidal Concentration (MBC)}

The MBC was determined by adding $100 \mu \mathrm{L}$ aliquots of the microplate well contents which did not show any growth in the MIC test, to the MH agar and then incubating at $37^{\circ} \mathrm{C}$ for $24 \mathrm{~h}$. The MBC was defined as the lowest concentration of the bark extract which showed no bacterial growth [43].

\subsection{Statistical Analysis}

All analyses were performed in triplicate. The results were expressed as means \pm standard deviations. The $\mathrm{IC}_{50}$ values were calculated by linear regression analysis. The statistics analysis was performed using SPSS software (version 22.0) by one-way analysis of variance (ANOVA). $p$-value $<0.05$ was regarded as significant.

\section{Conclusions}

In the current work, hispidulin and cirsimaritin were first identified from the bark extract of T. ramosissima in southern Xinjiang. Hispidulin, cirsimaritin, and isorhamnetin, abundant polyphenolics in the extract, were found at levels of $28.79,13.35$ and $36.91 \mu \mathrm{g} / \mathrm{mg}$ extract, respectively. The bark extract showed satisfying antioxidant activity with a similar DPPH scavenging activity and reducing power to ascorbic acid at 300, 400, and $500 \mu \mathrm{g} / \mathrm{mL}$. The bark extract exhibited excellent antibacterial activities against foodborne pathogens. L. monocytogenes, S. aureus and B. cereus were sensitive to the bark extract compared with E. coli, P.aeruginosa, S. typhimurium and S. castellani. L. monocytogenes was the most sensitive bacteria among these foodborne pathogens. Future investigation should focus on the effects of $T$. ramosissima on hazardous substance formation and sensory properties during food processing, as well as the potential health-promoting properties.

Author Contributions: Conceptualization, X.R., Z.P. and Y.Z.; Funding acquisition, Z.P.; Investigation, X.R.; Methodology, X.R., Y.B. and Y.Z.; Project administration, Z.P. and Y.Z.; Resources, X.Z.; Software, S.L.; Writing-original draft, X.R.; Writing—review and editing, Z.P. and G.Z.

Funding: This research was funded by the National Key R\&D Program of China (NO. 2018YFD0502306) and the Open Research Fund for Young Teachers in Nanjing Agricultural University and Tarim University (NO. TDNNLH201701).

Conflicts of Interest: The authors declare no conflict of interest.

\section{References}

1. Sultanova, N.; Makhmoor, T.; Abilov, Z.A.; Parween, Z.; Omurkamzinova, V.B.; Atta ur, R.; Choudhary, M.I. Antioxidant and antimicrobial activities of Tamarix ramosissima. J. Ethnopharmacol. 2001, 78, 201-205. [CrossRef]

2. Sehrawat, A.; Sultana, S. Tamarix gallica ameliorates thioacetamide-induced hepatic oxidative stress and hyperproliferative response in Wistar rats. J. Enzym. Inhib. Med. Chem. 2006, 21, 215-223. [CrossRef]

3. Yao, Y.; Jiang, C.S.; Sun, N.; Li, W.Q.; Niu, Y.; Han, H.Q.; Miao, Z.H.; Zhao, X.X.; Zhao, J.; Li, J. Tamaractam, a new bioactive Lactam from Tamarix ramosissima, induces apoptosis in rheumatoid arthritis fibroblast-like synoviocytes. Molecules 2017, 22, 96. [CrossRef]

4. Rahman, M.A.; Haque, E.; Hasanuzzaman, M.; Shahid, I.Z. Antinociceptive, Antiinflammatory and antibacterial properties of Tamarix indica roots. Int. J. Pharmacol. 2011, 7, 527-531. [CrossRef]

5. Ksouri, R.; Falleh, H.; Megdiche, W.; Trabelsi, N.; Mhamdi, B.; Chaieb, K.; Bakrouf, A.; Magne, C.; Abdelly, C. Antioxidant and antimicrobial activities of the edible medicinal halophyte Tamarix gallica L. and related polyphenolic constituents. Food Chem. Toxicol. 2009, 47, 2083-2091. [CrossRef] [PubMed]

6. Lee, K.G.; Shibamoto, T.; Takeoka, G.R.; Lee, S.E.; Kim, J.H.; Park, B.S. Inhibitory effects of plant-derived flavonoids and phenolic acids on malonaldehyde formation from ethyl arachidonate. J. Agric. Food Chem. 2003, 51, 7203-7207. [CrossRef]

7. Abouzid, S.F.; Ali, S.A.; Choudhary, M.I. A new ferulic acid ester and other constituents from Tamarix nilotica leaves. Chem. Pharm. Bull. 2009, 57, 740-742. [CrossRef] 
8. Bikbulatova, T.N.; Korul'kina, L.M. Composition of Tamarix hokenakeri and T. ramosissima. Chem. Nat. Compd. 2001, 37, 216-218. [CrossRef]

9. Mohammedi, Z.; Atik, F. Impact of solvent extraction type on total polyphenols content and biological activity from Tamarix aphylla (L.) Karst. Int. J. Pharm. Biol. Sci. 2011, 2, 609-615.

10. Parmar, V.S.; Bisht, K.S.; Sharma, S.K.; Jain, R.; Taneja, P.; Singh, S.; Simonsen, O.; Boll, P.M. Highly oxygenated bioactive flavones from Tamarix. Phytochemistry 1994, 36, 507-511. [CrossRef]

11. Umbetova, A.K.; Choudhary, M.I.; Sultanova, N.A.; Burasheva, G.S.; Abilov, Z.A. Flavonoids of plants from the genus Tamarix. Chem. Nat. Compd. 2005, 41, 728-729. [CrossRef]

12. Gao, H.; Wang, H.; Peng, J. Hispidulin induces apoptosis through mitochondrial dysfunction and inhibition of P13k/Akt signalling pathway in HepG2 cancer cells. Cell Biochem. Biophys. 2014, 69, 27-34. [CrossRef] [PubMed]

13. Yan, H.; Wang, H.; Ma, L.; Ma, X.; Yin, J.; Wu, S.; Huang, H.; Li, Y. Cirsimaritin inhibits influenza A virus replication by downregulating the NF-kB signal transduction pathway. Virol. J. 2018, 15, 88. [CrossRef] [PubMed]

14. Sultanova, N.; Makhmoor, T.; Yasin, A.; Abilov, Z.A.; Omurkamzinova, V.B.; Atta ur, R.; Choudhary, M.I. Isotamarixen-A new antioxidant and prolyl endopeptidase-inhibiting triterpenoid from Tamarix hispida. Planta Med. 2004, 70, 65-67. [CrossRef]

15. Ishak, M.S.; El-Sissi, H.I.; Nawwar, M.A.; El-Sherbieny, A.E. Tannins and polyphenolics of the galls of Tamarix aphylla I. Planta Med. 1972, 21, 246-253. [CrossRef] [PubMed]

16. Brand-Williams, W.; Cuvelier, M.E.; Berset, C. Use of a free radical method to evaluate antioxidant activity. LWT Food Sci. Technol. 1995, 28, 25-30. [CrossRef]

17. Xie, M.; Hu, B.; Wang, Y.; Zeng, X. Grafting of gallic acid onto chitosan enhances antioxidant activities and alters rheological properties of the copolymer. J. Agric. Food Chem. 2014, 62, 9128-9136. [CrossRef] [PubMed]

18. Oszmianski, J.; Wojdylo, A.; Lamer-Zarawska, E.; Swiader, K. Antioxidant tannins from Rosaceae plant roots. Food Chem. 2007, 100, 579-583. [CrossRef]

19. Yagi, K. A rapid method for evaluation of autoxidation and antioxidants. Agric. Biol. Chem. 1970, 34, $142-145$. [CrossRef]

20. Husain, S.R.; Cillard, J.; Cillard, P. Hydroxyl radical scavenging activity of flavonoids. Phytochemistry 1987, 26, 2489-2491. [CrossRef]

21. Juntachote, T.; Berghofer, E. Antioxidative properties and stability of ethanolic extracts of Holy basil and Galangal. Food Chem. 2005, 92, 193-202. [CrossRef]

22. Ksouri, R.; Megdiche, W.; Falleh, H.; Trabelsi, N.; Boulaaba, M.; Smaoui, A.; Abdelly, C. Influence of biological, environmental and technical factors on phenolic content and antioxidant activities of Tunisian halophytes. C. R. Biol. 2008, 331, 865-873. [CrossRef] [PubMed]

23. Benzie, I.F.F.; Strain, J.J. The ferric reducing ability of plasma (FRAP) as a measure of "antioxidant power": The FRAP assay. Anal. Biochem. 1996, 239, 70-76. [CrossRef] [PubMed]

24. Benzie, I.F.F.; Strain, J.J. Ferric reducing antioxidant power assay: Direct measure of total antioxidant activity of biological fluids and modified version for simultaneous measurement of total antioxidant power and ascorbic acid concentration. Methods Enzymol. 1999, 299, 15-27. [CrossRef] [PubMed]

25. Kong, K.W.; Mat-Junit, S.; Aminudin, N.; Ismail, A.; Abdul-Aziz, A. Antioxidant activities and polyphenolics from the shoots of Barringtonia racemosa (L.) Spreng in a polar to apolar medium system. Food Chem. 2012, 134, 324-332. [CrossRef]

26. Liu, L.; Sun, Y.; Laura, T.; Liang, X.; Ye, H.; Zeng, X. Determination of polyphenolic content and antioxidant activity of kudingcha made from Ilex kudingcha C.J. Tseng. Food Chem. 2009, 112, 35-41. [CrossRef]

27. Hidalgo, M.; Sanchez-Moreno, C.; de Pascual-Teresa, S. Flavonoid-flavonoid interaction and its effect on their antioxidant activity. Food Chem. 2010, 121, 691-696. [CrossRef]

28. Seo, S.; Seo, K.; Ki, S.H.; Shin, S.M. Isorhamnetin inhibits reactive oxygen species-dependent hypoxia inducible factor (HIF)-1 $\alpha$ accumulation. Biol. Pharm. Bull. 2016, 39, 1830-1838. [CrossRef]

29. Quan, Z.; Gu, J.; Dong, P.; Lu, J.; Wu, X.; Wu, W.; Fei, X.; Li, S.; Wang, Y.; Wang, J.; et al. Reactive oxygen species-mediated endoplasmic reticulum stress and mitochondrial dysfunction contribute to cirsimaritin-induced apoptosis in human gallbladder carcinoma GBC-SD cells. Cancer Lett. 2010, 295, 252-259. [CrossRef] 
30. Kim, B.H.; Choi, J.S.; Yi, E.H.; Lee, J.K.; Won, C.; Ye, S.K.; Kim, M.H. Relative antioxidant activities of quercetin and its structurally related substances and their effects on NF- $\mathrm{KB} / \mathrm{CRE} / \mathrm{AP}-1$ signaling in murine macrophages. Mol. Cells 2013, 35, 410-420. [CrossRef]

31. He, L.; Wu, Y.; Lin, L.; Wang, J.; Wu, Y.; Chen, Y.; Yi, Z.; Liu, M.; Pang, X. Hispidulin, a small flavonoid molecule, suppresses the angiogenesis and growth of human pancreatic cancer by targeting vascular endothelial growth factor receptor 2-mediated PI3K/Akt/mTOR signaling pathway. Cancer Sci. 2011, 102, 219-225. [CrossRef] [PubMed]

32. Chen, Y.T.; Zheng, R.L.; Jia, Z.J.; Ju, Y. Flavonoids as superoxide scavengers and antioxidants. Free Radic. Biol. Med. 1990, 9, 19-21. [CrossRef]

33. Osman, W.J.A.; Mothana, R.A.; Basudan, O.; Mohammed, M.S.; Mohamed, M.S. Antibacterial effect and radical scavenging activity of hispidulin and nepetin; a two flvaones from Tarconanthus camphoratus L. World J. Pharm. Res. 2015, 4, 424-433.

34. Scalbert, A. Antimicrobial properties of tannins. Phytochemistry 1991, 30, 3875-3883. [CrossRef]

35. Jayasinghe, C.; Gotoh, N.; Aoki, T.; Wada, S. Phenolics composition and antioxidant activity of sweet basil (Ocimum basilicum L.). J. Agric. Food Chem. 2003, 51, 4442-4449. [CrossRef] [PubMed]

36. Chang, C.C.; Yang, M.H.; Wen, H.M.; Chern, J.C. Estimation of total flavonoid content in propolis by two complementary colorimetric methods. J. Food Drug Anal. 2002, 10, 178-182.

37. Esteban-Fernandez, A.; Zorraquin-Pena, I.; Ferrer, M.D.; Mira, A.; Bartolome, B.; Gonzalez de Llano, D.; Victoria Moreno-Arribas, M. Inhibition of oral pathogens adhesion to human gingival fibroblasts by wine polyphenols alone and in combination with an oral probiotic. J. Agric. Food Chem. 2018, 66, 2071-2082. [CrossRef]

38. Yang, L.C.; Li, R.; Tan, J.; Jiang, Z.T. Polyphenolics composition of the leaves of Zanthoxylum bungeanum maxim. grown in Hebei, China, and their radical scavenging activities. J. Agric. Food Chem. 2013, 61, 1772-1778. [CrossRef]

39. Liu, F.; Ooi, V.E.C.; Chang, S.T. Free radical scavenging activities of mushroom polysaccharide extracts. Life Sci. 1997, 60, 763-771. [CrossRef]

40. Li, H.; Wang, Q.J. Evaluation of free hydroxyl radical scavenging activities of some Chinese herbs by capillary zone electrophoresis with amperometric detection. Anal. Bioanal. Chem. 2004, 378, 1801-1805. [CrossRef]

41. Ye, Z.; Wang, W.; Yuan, Q.; Ye, H.; Sun, Y.; Zhang, H.; Zeng, X. Box-Behnken design for extraction optimization, characterization and in vitro antioxidant activity of Cicer arietinum L. hull polysaccharides. Carbohydr. Polym. 2016, 147, 354-364. [CrossRef] [PubMed]

42. Ebani, V.V.; Nardoni, S.; Bertelloni, F.; Giovanelli, S.; Rocchigiani, G.; Pistelli, L.; Mancianti, F. Antibacterial and antifungal activity of essential oils against some pathogenic bacteria and yeasts shed from poultry. Flavour Frag. J. 2016, 31, 302-309. [CrossRef]

43. Bassanetti, I.; Carcelli, M.; Buschini, A.; Montalbano, S.; Leonardi, G.; Pelagatti, P.; Tosi, G.; Massi, P.; Fiorentini, L.; Rogolino, D. Investigation of antibacterial activity of new classes of essential oils derivatives. Food Control 2017, 73, 606-612. [CrossRef]

Sample Availability: Samples of the compounds (isorhamnetin, hispidulin, cirsimaritin, and quercetin) are not available from the authors.

(C) 2019 by the authors. Licensee MDPI, Basel, Switzerland. This article is an open access article distributed under the terms and conditions of the Creative Commons Attribution (CC BY) license (http:/ / creativecommons.org/licenses/by/4.0/). 